\title{
Determinants of self-rated health in an Irish deprived suburban population - a cross sectional face-to-face household survey
}

\author{
Catherine D. Darker ${ }^{1 *}$, Erica Donnelly-Swift ${ }^{2}$, Lucy Whiston ${ }^{1}$, Fintan Moore ${ }^{1}$ and Joe M. Barry ${ }^{1}$
}

\begin{abstract}
Background: Self-rated health (SRH) is amongst the most frequently assessed health perceptions in epidemiological research. While there is a growing understanding of the role of SRH, a paradigm model has yet to be widely accepted with recent studies concluding that further work is required in determining whether there are important predictors of $\mathrm{SRH}$ yet to be highlighted. The aim of this paper is to determine what health and non-health related factors were associated with SRH in a suburban deprived population in Dublin, Ireland.

Methods: A cross sectional face-to-face household survey was conducted. Sampling consisted of random cluster sampling in 13 electoral divisions, with a sampling frame of 420 houses. Demographic information relating to the primary carer was collected. Health status of the primary carer was measured through SRH. Household level data included the presence or absence of persons with a chronic disease, persons who smoked, persons with a disability and healthcare utilisation of general practitioner and hospital level services. A logistic regression model was utilised in the analysis whereby the odds of primary carers with poor SRH were compared to the odds of carers with good SRH taking health and non-health related factors into account.
\end{abstract}

Results: Of the 420 households invited to participate a total of 343 were interviewed ( $81.6 \%$ response rate). Nearly half of the primary carers indicated their health as being 'good' ( $n=158 / 342 ; 46.2 \%)$.

Adjusting for the effects of other factors, the odds of primary carers with second level education were increased for having poor SRH in comparison to the odds of those with third level education (OR 3.96, $95 \% \mathrm{Cl}(1.44,11.63))$. The odds of primary carers who were renting from the Council were increased for having poor SRH compared to the odds for

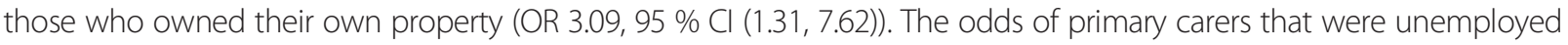
(OR 3.91, $95 \% \mathrm{Cl} 1.56,10.25))$ or retired, ill or unable to work (OR 4.06, $95 \% \mathrm{Cl}(1.49,11.61))$ were higher for having poor $\mathrm{SRH}$ than the odds of those in employment. If any resident of the household had a chronic illness then the odds of the primary carer were increased for having poor SRH compared to the odds for a primary carer in a household where no resident had a chronic illness (OR 4.78, $95 \% \mathrm{Cl}(2.09,11.64)$ ). If any resident of the household used the local hospital, the odds of the primary carer were increased for having poor SRH compared to the odds for the primary carer in a household where no resident used the local hospital (OR 2.01, $95 \% \mathrm{Cl}(1.00,4.14))$.

Conclusions: SRH is affected by both health and non-health related factors. SRH is an easy to administer question that can identify vulnerable people who are at risk of poor health.

Keywords: Self-rated health, Predictor, Community, Deprivation, Education, Employment, Chronic illness, Hospital use

\footnotetext{
* Correspondence: catherine.darker@tcd.ie

${ }^{1}$ Public Health \& Primary Care, Institute of Population Health Trinity College

Dublin, Tallaght Cross, Dublin 24 D24 DH74, Ireland
}

Full list of author information is available at the end of the article

\section{Biomed Central}

(c) 2016 The Author(s). Open Access This article is distributed under the terms of the Creative Commons Attribution 4.0 International License (http://creativecommons.org/licenses/by/4.0/), which permits unrestricted use, distribution, and reproduction in any medium, provided you give appropriate credit to the original author(s) and the source, provide a link to the Creative Commons license, and indicate if changes were made. The Creative Commons Public Domain Dedication waiver (http://creativecommons.org/publicdomain/zero/1.0/) applies to the data made available in this article, unless otherwise stated. 


\section{Background}

Self-rating of health (SRH), based on a simple question such as "How would you rate your health?" is one of the most frequently employed health measures in large scale general population research [1]. It has been used to examine the relationship between health and a wide range of social and economic factors, including educational attainment [2-5], occupational status [4, 5], deprivation [6, 7], social capital [8-10], age and gender [11]. Despite its brevity SRH is a multifaceted paradigm that is informed by an individual's cognitive awareness and their experience of their personal physiological, psychological and sociological health [12-14]. In Ireland SRH was included in the national census data for the first time in 2011 [15], with approximately $88 \%$ of the population rating their health as 'very good' or 'good', $8 \%$ as 'fair' and $2 \%$ rating their health as either 'bad or very bad' [16]. This is considerably higher than the Organisation for Economic Cooperation and Development (OECD) average of just $69 \%$ of the adult population (aged over 15) rating their health as 'good' or 'very good' [17].

The social gradient in health, disease and mortality is one of the most widely observed and consistent findings in international epidemiological research [18-20]. A recent study in Australia demonstrated the need to consider deprivation levels within communities in relation to SRH [6]. Neighbourhood deprivation (both physical and social) is associated with lower collective efficacy, trust, and social capital, and higher levels of social and physical disorder, fear of crime, and racism. This demonstrates the relationship between neighbourhood deprivation and SRH is mediated by the social and physical characteristics of the area [21]. This emphasises the importance of studying the multilevel structure of disadvantage, and indeed whether there is a double disadvantage, when considering SRH.

A number of studies have shown SRH to be a strong, consistent predictor of morbidity and mortality across varied populations, even after adjustment for confounding factors such as age, sex, and prior clinical history [6,13,14, 22-25]. Individuals with poor SRH have been found to have between two and five times higher risk of death compared with individuals who reported good SRH after two to twenty eight years of follow up [13, 14, 23-25]. SRH has been found to be a significant predictor of onset of chronic disease among US adults aged over 50 years including cardiovascular diseases (CVD), arthritis, diabetes, lung disease and stroke [26]. The relationship between SRH and other health outcomes including chronic disease incidence, diabetes complications, physical and cognitive functional limitations, health services use, and clinical biomarkers have also been investigated [27-31]. A high $\mathrm{SRH}$ was found to be associated with lower risk of vascular events and major complications in type 2 diabetics in a longitudinal cohort study of over 7000 patients [31]. Living with a person with a chronic illness has also been shown to be associated with lower SRH [26, 31, 32].

$\mathrm{SRH}$ is an active cognitive process, consisting of several stages, that is not guided by formal, agreed rules or definitions of health but lies at the cross roads of culture and biology. A unified conceptual model of SRH outlines the complicated process, which determines a person self-assessment of their own health status. This involves a determination of the cultural and historical varying concepts of 'health'; personal reference groups that the individual draws from, early health experiences, health expectations, positive or negative dispositions and cultural conventions [33]. The perception of health status is not a static phenomenon but rather one that changes with new 'information'. Human judgements are based on multiple psychological processes, which are subject to internal and external influences [34]. With this in mind, the theoretical framework of the International Classification of Functioning, Disability and Health (ICF) [35] was used to create a better understanding of factors associated with SRH [36]. This demonstrated that SRH had an independent association with five variables representing ICF body functions, activities and personal factors.

Nonetheless a complex relationship exists between $\mathrm{SRH}$ and health-related behaviours. Health-related behaviours included in SRH studies often include smoking status, dietary assessments, physical activity, body mass index (BMI) or presence of obesity, and alcohol consumption [32]. Physical activity has been shown to have a relationship with SRH in a number of studies with associations between higher levels of physical activity and better SRH [37] and a lack of regular physical activity associated with poorer SRH [38]. The experience of stress has been positively associated with poor SRH [39] with women in particular reporting higher stress than their male counterparts [39, 40]. Conflicting findings have emerged concerning the relationship between $\mathrm{SRH}$ and smoking, alcohol consumption, and dietary behaviours [30, 41-46]. Health behaviours have been shown to mediate the relationship between SRH and mortality, and this effect often differs by gender and/or duration of effect [29, 47, 48]. Layes et al. [49] determined that individuals who engaged in healthy lifestyles were actually more likely to be pessimistic regarding their health status.

Understanding how health and non-health factors affect health through their relationship with $\mathrm{SRH}$ is important in developing effective health policies and for future health planning. A paradigm model of the factors which influence SRH has yet to be fully understood and accepted, with further research necessary $[1,50]$. 


\section{Methods}

Aim

The aim of this paper is to answer the following research question - what health and non-health related factors predict SRH in a suburban deprived population in Dublin, Ireland? This maps onto the study hypothesis, that SRH will be associated with both health and nonhealth related factors.

\section{Design}

A cross sectional face-to-face household survey of the health assets and needs assessment (HANA) relating to the health and wellbeing of a suburban deprived community of South Dublin, Ireland.

\section{Setting and sampling}

The sampling process closely followed a health needs assessment study conducted in the same geographical area in 2001 [51, 52]. Deprivation is a state of "observable and demonstrable disadvantage relative to the local community to which an individual belongs" [53]. Deprivation has a role to play in terms of health status $[6,7]$ and service uptake [54] and therefore it was necessary to take account of this factor when selecting the sample. The Small Area Health Research Unit (SAHRU) of the Department of Public Health \& Primary Care at Trinity College Dublin has developed a deprivation index (DI) for health and health services research. The most recent SAHRU DI, based upon national census data for 2011, utilises four indicators to determine the classification of deprivation [55]; unemployment, low social class, no car and government funded housing. The DI score ranges from one to ten, where one is least deprived and ten is most deprived.

Sampling consisted of random cluster sampling in 13 electoral divisions (EDs) in a suburban deprived area of South Dublin. There were a total of $n=24,998$ households in the EDs. An ED is the smallest legally defined administrative area in Ireland for which Small Area Population Statistics are published from the national census [15]. The households were partitioned into clusters. A SAHRU DI score was applied to each cluster. A systematic sample of clusters was selected consisting of 30 clusters from a high deprivation group of EDs and 30 clusters from a low deprivation group of EDs with each cluster consisting of seven adjacent houses. This yielded a total sampling frame of 420 households Fig. 1.

\section{Procedure}

The study was advertised in the local area and general practitioners were informed of the study through an information letter. Letters were sent to 420 randomly selected households, inviting the primary carers to participate in the survey. The primary carer was identified as the person in the household who manages the welfare and health of the family/household. In a house of renters this was the person who pays the bills or whose name was on the rent agreement. Interviewers were rigorously trained in the survey methodology. Three members of the research team (CD, JB \& LW) conducted a half-day training session. This consisted of the background, context and purpose of the study, the questionnaire, informed consent and the working alone procedures. Role-plays were employed to familiarise the data collectors with the questionnaire and surrounding procedures. The quality of data collection was assessed when the first batch of questionnaires were returned. Questionnaires were assessed for any errors and issues identified were discussed with the data collectors. Data collectors were also offered an opportunity to ask questions or clarify any concerns they had relating to data collection procedures or the questionnaire. Each interviewer elicited informed written consent from each primary carer before the interview commenced.

\section{Measures}

The questionnaire consisted of a range of different topics; demographic information relating to the primary carer such as employment status, house occupancy status, and level of health cover. Some questions were at the level of the individual primary carer level, while other questions were at the household level. Depending on the number of residents in each household questionnaires took 20 to $30 \mathrm{~min}$ to complete.

\section{Health status}

Health status of the primary carer, was measured through administration of a range of validated instruments measuring SRH, social capital, physical activity and stress experienced, including symptoms resulting from stress experienced.

\section{Self reported health (SRH)}

$\mathrm{SRH}$ was assessed by the answer to a single item 'How is your health in general?'. There were five response categories: 'very good, 'good,' 'fair', 'bad', and 'very bad'. This question has become a standard measure for SRH and due to its format can be compared with Irish and international data [15]. This question has been employed in the national Census of Ireland in 2011 and 2016. For analysis this variable was collapsed into 'good self-rating of health' consisting of 'very good' and 'good'. 'Fair,' 'bad' and 'very bad' were collapsed to make up 'poor selfrating of health'. The collapse of answer categories was determined by those who answered 'fair' having poorer health than those who answered 'good' or 'very good'.

\section{Physical activity}

Four questions assessed primary carers' levels of physical activity. The number of times severe, moderate and mild 


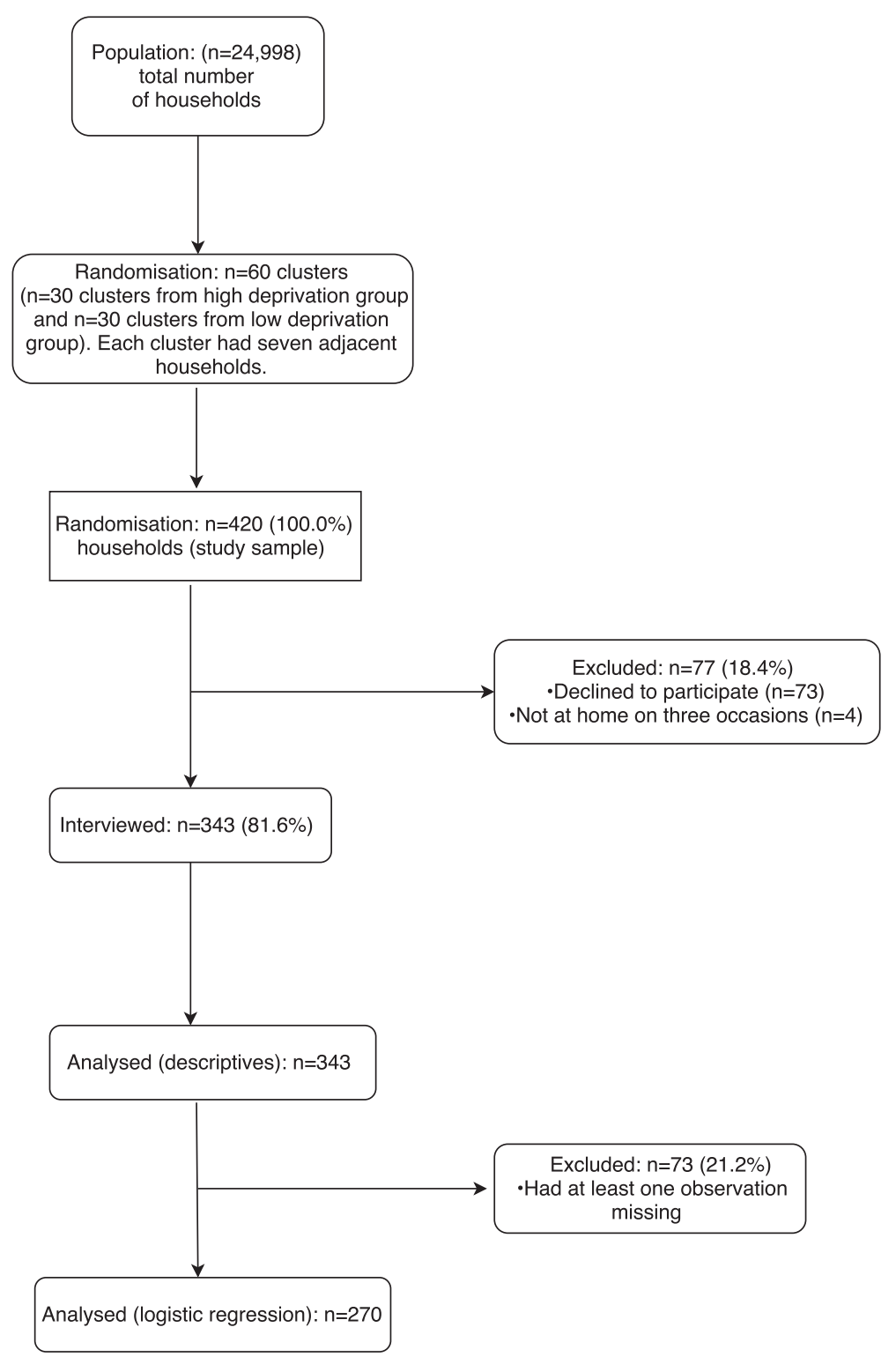

Fig. 1 Flow diagram of study participants

physical activity was engaged in for more than 20 min during an average week was recorded along with the number of days in an average week that the primary carer walked for more than $30 \mathrm{~min}$. These questions asked in the 2002 Survey of Lifestyle, Attitudes and Nutrition survey (SLAN) were adapted from the International Physical Activity Questionnaire (IPAQ) [56]. This enabled the employment of the IPAQ scoring protocol to assign primary carers to categories based on levels of physical activity. The IPAQ has been shown to be a valid and reliable measure of physical activity with repeatable data and criterion validity with a median of $0.30[56,57]$.

\section{Level of healthcare cover}

In Ireland there is a two-tier health service; state provided general medical (primary care) services (known as GMS 'medical card') to those households on low income (just over $40 \%$ of the population [58]) and the remainder who may either be privately insured or pay out-of-pocket for their healthcare.

\section{Stress}

Stress was assessed by answers to a number of items used in a previous study [51]. Firstly, respondents were asked "Have you experienced stress within the last 12 months?". If this item was answered positively then a 
number of questions gathered further information about the stress, such as reason for stress, scale of the problem, symptoms experienced due to stress and steps taken as a result. These questions have previously been employed with a similar population through a previous cross sectional study conducted within the same suburban deprived area in 2001 [51].

Household level data included demographic information for all people living in the house, the presence or absence of a person living in the household with a chronic disease, whether the household contained a person who smoked, whether any member of the household was in receipt of a disability benefit and healthcare utilisation of general practitioner and hospital level services. (See Additional file 1 for copy of survey instrument).

\section{Analyses}

This study adopts a logistic regression model, to examine the odds of primary carers with poor SRH compared to the odds of carers with good SRH, taking health and nonrelated health factors into account.

Fixed effects classified in the model were demographic characteristics, house occupancy status, level of health cover and health status characteristics. A random intercept was included in the model to account for cluster variation. Information criterion and likelihood ratio tests were used to evaluate goodness of fit. Akaike's information criterion (AIC) considers both error and the principle of parsimony. AIC penalises a model for too many parameters. Bayesian information criterion (BIC) is an alternative to AIC. BIC takes sample size into consideration and is slower to be drawn toward more complex models as sample size increases [59]. Receiver operating characteristic (ROC) curve and area under the curve (AUC) were used to examine sensitivity and specificity. The ROC curve is a graphical plot of sensitivity versus 1-specificity. If perfect sensitivity and specificity were obtained then the curve would appear as a right angle. AUC was estimated using an asymptotically exact method (DeLong's Method), which evaluates the uncertainty of the area under the curve.

Generalised variance inflation factors (GVIF) and adjusted GVIF were examined to determine the presence of multicollinearity. (Adjusted GVIF accounts for the dimensionality of the confidence ellipsoid and equals $(\mathrm{GVIF})^{\wedge}(1 /(2 \mathrm{df}))$ where $\mathrm{df}$ denotes degree of freedom associated with the factor) [60].

Results are displayed in terms of odds ratios (OR) and $95 \%$ confidence intervals $(\mathrm{CI})$. ORs have a range from 0 to infinity. A value of 1.0 means there is no difference in odds. ORs greater than 1.0 indicate that the ratio of those with poor SRH versus good SRH in the selected group is greater than the baseline group. If the $95 \% \mathrm{CI}$ for OR contains 1 in the interval this indicates that at the $5 \%$ significance level, there is no evidence to suggest that the ratio of those with poor SRH (versus good SRH) for the selected group are different from the baseline group.

All statistical analysis was performed using statistical software $R$ (version 3.2.2) [61] and software packages lme4 (Linear Mixed-Effects Models using 'Eigen' and S4) [62] package pRoc (Display and Analyze ROC Curves) [63] and package car (Companion to Applied Regression) [60].

\section{Results \\ Response rate}

Of the 420 households invited to participate in the survey 343 were interviewed. This is a response rate of $81.6 \%$. The remainder were either un-contactable, or refused for reasons such as they did not have time to take part or had no interest in the research.

\section{Descriptive analyses}

A demographic and socioeconomic description of the primary carers is reported (Table 1). The majority of primary carers were female, aged between 50 and 64 years of age, of Irish nationality, married, with mid-second level education, working full time, in receipt of a medical card, physically active and had experienced stress in the previous 12 months. Nearly half of primary carers indicated their health as being 'good' ( $n=158 / 342 ; 46.2 \%)$.

A description of household occupancy status, number of people living within each household, whether there is a person with a chronic illness, a disability, and a smoker within the household is also reported, alongside healthcare utilisation in the previous 12 months (Table 2).

\section{Regression analyses}

Seventy-three household responses contained at least one missing observation. Thus, the complete data set was composed of 270 household responses. Table 3 shows the counts of poor SRH and good SRH for each variable, which corresponds to the data pertaining to the logistic regression analyses. Table 4 shows the characteristics of missing data for primary carers with poor SRH and good SRH.

Results from the logistic regression model including random effect indicated that the unexplained variation within each cluster had a very low estimated standard deviation $(<0.0001)$. In the principle of parsimony the logistic regression model without a random effect is adequate. This model gives results (effect estimates and standard error values) that are nearly the same as the results of the logistic regression model which includes a random effect. (The deviance between the logistic regression model and the logistic model including a random effect increases by 0.02 . This difference in deviance is approximately chi-squared with one degree of freedom ( $p$-value $=0.45$, note: this $p$-value for comparing both models is half the $p$-value obtained from treating 
Table 1 Demographic and socioeconomic characteristics of the primary carer $(N=343)$

\begin{tabular}{lll}
\hline Indicator & Number & $\%$ \\
\hline Gender $(N=343 / 343 ; 100 \%)$ & & \\
$\quad$ Female & 237 & $69.1 \%$ \\
$\quad$ Male & 106 & $30.9 \%$ \\
Age $(N=339 / 343 ; 98.8 \%)$ & & \\
$20-34$ & 65 & $19.2 \%$ \\
$35-49$ & 93 & $27.4 \%$ \\
$50-64$ & 113 & $33.3 \%$ \\
$65+$ & 68 & $20.1 \%$
\end{tabular}

Nationality $(N=325 / 343 ; 94.8 \%)$

Irish

Other

$91.7 \%$

Marital status ( $N=342 / 343 ; 99.7 \%)$

Married
Separated, divorced, widowed
Single
Cohabitating

Highest level of education attained ( $N=337 / 343 ; 98.3 \%$ )

Primary education or less

Junior or intermediate certificate, technical

or vocational training

Leaving certificate, A-level

Non-degree qualification

Degree, professional qualification or both

Postgraduate qualification

Current employment status ( $N=343 / 343 ; 100 \%)$

Working full time

Retired

Working in the home

Unemployed

Working part time

III/unable to work

In education

Government Employment Programme

Level of health cover $(N=341 / 343 ; 99.4 \%)$

Medical card ${ }^{\mathrm{a}}$
Neither medical card nor private health insurance
Private health insurance
Doctor visit card

Physical activity IPAQ score ( $N=324 / 343 ; 94.5 \%)$

Active

Inactive

Stress experienced in the last 12 months? ( $N=341 / 343 ; 99.4 \%)$

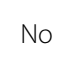

Yes

$8.3 \%$

$52.3 \%$

$21.1 \%$

$19.6 \%$

$7.0 \%$

$26.7 \%$

$22.3 \%$

$16.3 \%$

$20.5 \%$

$12.2 \%$

$2.1 \%$

$27.4 \%$

$20.7 \%$

$15.7 \%$

$14.9 \%$

$13.7 \%$

$5.5 \%$

$1.7 \%$

$0.3 \%$

187

$54.8 \%$

$29.0 \%$

$13.8 \%$

$2.3 \%$

$62.3 \%$

$37.7 \%$

No
Table 1 Demographic and socioeconomic characteristics of the primary carer $(N=343)$ (Continued)

\begin{tabular}{lll}
\hline Self-rating of health $(N=342 / 343 ; 99.7 \%)$ & & \\
Very good & 84 & $24.6 \%$ \\
Good & 158 & $46.2 \%$ \\
Fair & 76 & $22.2 \%$ \\
Bad & 19 & $5.6 \%$ \\
Very bad & 5 & $1.5 \%$
\end{tabular}

a State provided general medical (primary care) services (GMS) to those households on low income

deviance as chi-squared with $1^{\circ}$ of freedom) [59]. AIC for the random effects model is 269.27 and is 267.23 for the simplified model with variance $=0$. Similarly BIC for the random effects model is 373.63 and is 368.03 for the less complex model.

The null deviance, which denotes the null model with just the constant term, was 322.8 and residual deviance

Table 2 Characteristics of the households $(N=343)$

\begin{tabular}{lll}
\hline Indicator & Number & $(\%)$ \\
\hline Household occupancy status ( $N=336 / 343 ;$ & $98.0 \%)$ & \\
Outright owner/ Mortgage & 203 & 60.4 \\
Renting privately & 29 & 8.6 \\
$\begin{array}{l}\text { Renting from or rent paid by health } \\
\text { board/county council }\end{array}$ & 104 & 31.0 \\
Number of people living in the household $(N=341 / 343 ; 99.4 \%)$ \\
1 to 2 people & 140 & 41.1 \\
3 to 4 people & 142 & 41.6 \\
5 to 11 people & 59 & 17.3 \\
Median & 3.0 &
\end{tabular}

Does a person with a chronic illness live in the household? $(N=335 / 343 ; 97.7 \%)$

$\begin{array}{lll}\text { No } & 161 & 48.1 \\ \text { Yes } & 174 & 51.9\end{array}$

Does a person with a disability live in the household? $(N=330 / 343 ; 96.2 \%)$

$\begin{array}{lll}\text { No } & 272 & 82.4 \\ \text { Yes } & 58 & 17.6\end{array}$

Does a smoker live in the household? ( $N=340 / 343 ; 99.1 \%)$

$\begin{array}{lll}\text { No } & 189 & 55.6 \\ \text { Yes } & 151 & 44.4\end{array}$

Has a member of the household used the local hospital in the previous 12 months? ( $N=342 / 343 ; 99.7 \%)$

$\begin{array}{lll}\text { No } & 149 & 43.6 \\ \text { Yes } & 193 & 56.4\end{array}$

Did anyone in the household use general practice services in the previous 12 months? ( $N=341 / 343 ; 99.4 \%)$

\begin{tabular}{lll} 
No & 18 & 5.3 \\
Yes & 323 & 94.7 \\
\hline
\end{tabular}


Table 3 Characteristics of primary carers with poor SRH and good SRH

\begin{tabular}{lll}
\hline Note: 1 missing value for SRH & $\begin{array}{l}\text { Good SRH } \\
(N=242)\end{array}$ & $\begin{array}{l}\text { Poor SRH } \\
(N=100)\end{array}$ \\
\hline
\end{tabular}

\begin{tabular}{lllll} 
& $(N=242)$ & \multicolumn{3}{c}{$(N=100)$} \\
\hline Gender & & & & \\
Male & 71 & $29.3 \%$ & 35 & $35.0 \%$ \\
Female & 171 & $70.7 \%$ & 65 & $65.0 \%$
\end{tabular}

Age

$20-34$
$35-49$
$50-64$
$65+$
Missing

Marital

Married
Single
Co-habiting
Separated/divorced/widowed
Missing

Education

Third level
Primary
Junior certificate $^{a}$
Leaving certificate $^{\mathrm{b}}$
Missing

Employment

Employed
Unemployed
Retired, ill or unable to work
Missing
Health Cover

Private health insurance
Medical card
None
Missing
Occupancy

Owner/mortgage
Renting privately
Renting - council
Missing

Number people in household

1
2
$3-5$
$6+$
Missing

$\begin{array}{llll}51 & 21.1 \% & 14 & 14.0 \% \\ 73 & 30.2 \% & 20 & 20.0 \% \\ 74 & 30.6 \% & 39 & 39.0 \% \\ 41 & 16.9 \% & 26 & 26.0 \% \\ 3 & 1.2 \% & 1 & 1.0 \%\end{array}$

51

$53.3 \% \quad 50$

$21.1 \% \quad 16$

$7.0 \% \quad 7$

$18.2 \% \quad 27$

$0.4 \% \quad 0$

$40.1 \% \quad 20$

$23.1 \% \quad 19$

$14.9 \% \quad 19$

$0.8 \% \quad 4$

124

66

52

0

41

115

84

2

$51.2 \% \quad 18$

$27.3 \% \quad 39$

$21.5 \% \quad 43$

$0.0 \% \quad 0$

$16.9 \% \quad 6$

$47.5 \% \quad 79$

$34.7 \% \quad 15$

$0.8 \% \quad 0$

155

18

65

4

\section{5}

61

128

27

1

$0.0 \%$

$0.0 \%$

$6.0 \%$
$21.1 \% 38$

$50.0 \%$

$16.0 \%$

$7.0 \%$

$27.0 \%$

$20.0 \%$

$38.0 \%$

$19.0 \%$

$19.0 \%$

$4.0 \%$

$18.0 \%$

$39.0 \%$

$79.0 \%$

$15.0 \%$

$0.0 \%$

$11.0 \%$

$39.0 \%$

$3.0 \%$
Table 3 Characteristics of primary carers with poor SRH and good SRH (Continued)

Stress

No

Yes

Missing

$37.2 \% \quad 21$

$21.0 \%$

Chronic Illness

$\begin{array}{lllll}\text { No } & 138 & 57.0 \% & 23 & 23.0 \% \\ \text { Yes } & 100 & 41.3 \% & 73 & 73.0 \% \\ \text { Missing } & 4 & 1.7 \% & 4 & 4.0 \%\end{array}$

Disability

$\begin{array}{lllll}\text { No } & 205 & 84.7 \% & 66 & 66.0 \%\end{array}$

Yes

Missing

$11.2 \% \quad 31$

$31.0 \%$

Smoker

$4.1 \% \quad 3 \quad 3.0 \%$

No

Yes

Missing

IPAQ

Active

Inactive

Missing

27

10

$3.0 \%$

Local hospital use

No

Yes

Missing

GP use

$43.0 \% \quad$ No

Yes

Missing

138

$57.0 \% \quad 50 \quad 50.0 \%$

$102 \quad 42.1 \% \quad 49 \quad 49.0 \%$

$2 \quad 0.8 \% \quad 1 \quad 1.0 \%$

Social Cohesion

No
Yes

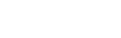

$56.0 \%$

Missing

$\begin{array}{lllll}146 & 60.3 \% & 56 & 56.0 \% \\ 80 & 33.1 \% & 41 & & 41.0 \%\end{array}$

$16 \quad 6.6 \% \quad 3 \quad 3.0 \%$

Junior or intermediate certificate, technical or vocational training

bLeaving certificate, A-Level

'State provided general medical (primary care) services (GMS) to those

households on low income

was 220.22. This gives a difference of 102.58 , with degrees of freedom $=19$. Thus, the fitted model is more informative than the null model.

The issue of multicollinearity was not present as all adjusted GVIF values had a value less than 2. Table 5 shows results of the logistic regression model (with no random effects). Crude and adjusted odds ratios for primary carers with poor SRH compared with those with good SRH are displayed. ORs were based on the 
Table 4 Characteristics of missing observations for primary carers with poor SRH and good SRH $(n=73)$

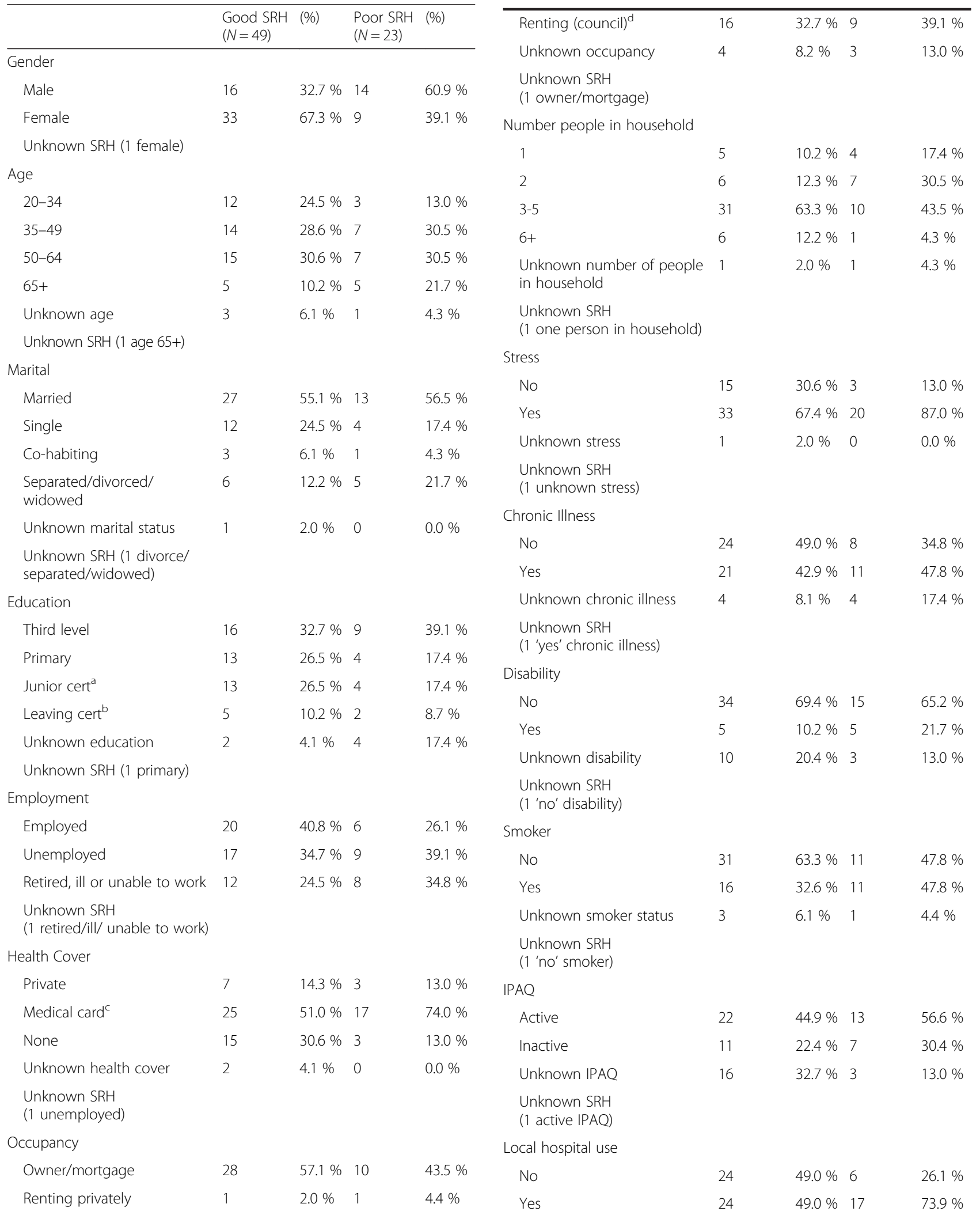

Table 4 Characteristics of missing observations for primary carers with poor SRH and good SRH $(n=73)$ (Continued)

umber people in household 
Table 4 Characteristics of missing observations for primary carers with poor SRH and good SRH ( $n=73)$ (Continued)

\begin{tabular}{lllll}
\hline Unknown local hospital use & 1 & $2.0 \%$ & 0 & $0.0 \%$ \\
Unknown SRH & & & & \\
(1 'yes' local hospital use) & & & & \\
GP use & 4 & $8.2 \%$ & 0 & $0.0 \%$ \\
No & 43 & $87.7 \%$ & 23 & $100.0 \%$ \\
Yes & 2 & $4.1 \%$ & 0 & $0.0 \%$ \\
Unknown GP use & & & & \\
Unknown SRH & & & & \\
(1 'yes' GP use) & & & & \\
Social Cohesion & 23 & $46.9 \%$ & 8 & $34.8 \%$ \\
No & 23 & $46.9 \%$ & 12 & $52.2 \%$ \\
Yes & 3 & $6.1 \%$ & 3 & $13.0 \%$ \\
Unknown social cohesion & & & \\
Unknown SRH (1 'no' SRH) & & &
\end{tabular}

Junior or intermediate certificate, technical or vocational training

bLeaving certificate, A-Level

'State provided general medical (primary care) services (GMS) to those households on low income

${ }^{\mathrm{d}}$ Renting from or rent paid by health board/county council

complete data set (where missing values were omitted from the analysis).

Model evaluations indicate that this model is accurate in terms of sensitivity and specificity (see Fig. 2 for corresponding ROC curve). AUC was estimated to be 0.85 (95 \% CI: 0.79-0.89).

Statistically significant factors include level of education, employment, occupancy, number of people living in household, chronic illness and local hospital use. Adjusting for the effects of other factors, the odds of primary carers who had primary education (OR 3.96, 95 \% CI $(1.44,11.63)$ ), junior certificate (or intermediate certificate, technical or vocational training) (OR 3.25, $95 \% \mathrm{CI}(1.09,10.09))$ or leaving certificate (A-levels or technical qualification) (OR $3.8995 \%$ CI $(1.38,11.57))$ were greater to have poor selfrated health in comparison to primary carer's with third level education. The odds of primary carers who were renting privately (OR 5.09, $95 \%$ CI $(1.36,19.83)$ ) or renting from, or having rent paid in by the health board/county council (OR 3.09, 95 \% CI $(1.31,7.62)$ ) were increased for poor SRH in comparison to the odds to self-rated health than primary carers who owned their own property outright or who had a mortgage. The odds of primary carers who were unemployed (OR $3.91,95 \%$ CI $(1.56,10.25))$ or retired, ill or unable to work (OR 4.06, 95 \% CI $(1.49,11.61))$ were greater for having poor SRH than the odds of primary carers who had employment. If any resident of the household had a chronic illness then the odds of a primary carer having poor selfrated health was greater than the odds for a primary carer in a household where no resident had a chronic illness
(OR 4.78, $95 \%$ CI $(2.09,11.64)$. If any resident of the household used the local hospital, the primary carer had greater odds of having poor self-rated health than the odds for a primary carer in a household where no resident used the local hospital (OR 2.01, 95 \% CI $(1.00,4.14)$ ).

\section{Discussion}

Self-rating of health (SRH) is affected by both health and non-health related factors. Nearly half of the primary carers in the current study reported their heath as 'good'. Of those that reported their health as being 'poor' factors, such as, educational attainment, employment status, whether a person owns their own home, whether there was someone living in the household with a chronic illness and whether any of the household residents had used the local hospital, had a role to play in the primary carer reporting poorer SRH.

While there is a growing understanding of the role of $\mathrm{SRH}$, a paradigm model has yet to be widely accepted with recent studies concluding that further work is required in determining whether there are important predictors of SRH yet to be highlighted $[1,50]$. The relationship between the biological and physiological mechanisms through which SRH results in chronic disease in the presence of physical, psychosocial and environment stressors has been explored [64]. A further consideration is the need to control for differences in reporting behaviour. A growing literature shows that respondents tend to evaluate their health differently according to a number of non-health characteristics [33, 49, 65], including age, gender and education and failure to account for these factors may bias the estimated associations between health dimensions and SRH [1].

Self-rating of health is commonly used in large population level research due to its ease of use and its power in measuring health. The same questions on self-rating of health were put to primary carers in the 2014 HANA survey and to all people living within each household in the 2011 National Census within the same geographical area. Respondents in the HANA survey gave a lower rating of their overall health status (70.8 \% reporting 'very good' or 'good' health status) than respondents from the same electoral divisions during the census (89.9\%). The disparity between the two time points in how participants rank their health may be due to the greater focus on health in the survey in 2014 as opposed to the 2011 national census which asks a broad range of questions, such as whether the house had piped water and sewage facilities and access to the internet. Alternatively, this difference could be due to the national census being self-completed and the HANA survey being researcher administered.

We found no evidence to support the role of age, gender and marital status in SRH, which would differ from previously published research $[11,66,67]$. 
Table 5 Factors associated with poor self-rated health

\begin{tabular}{|c|c|c|c|c|}
\hline & $\begin{array}{l}\text { Crude } \\
\text { OR }\end{array}$ & $95 \% \mathrm{Cl}$ & $\begin{array}{l}\text { Adjusted } \\
\mathrm{OR}^{\mathrm{a}}\end{array}$ & $95 \% \mathrm{Cl}$ \\
\hline \multicolumn{5}{|l|}{ Age group (years) } \\
\hline $20-34$ & 1.28 & $(0.51,3.15)$ & 2.81 & $(0.87,9$ \\
\hline $35-49$ & Base & & Base & \\
\hline $50-64$ & 2.46 & $(1.20,5.29)$ & 1.67 & $(0.55,5$ \\
\hline $65+$ & 2.65 & $(1.20,6.05)$ & 1.41 & $(0.33,6$. \\
\hline \multicolumn{5}{|l|}{ Gender } \\
\hline Male & Base & & Base & \\
\hline Female & 0.78 & $(0.45,1.39)$ & 0.67 & $(0.32,1$. \\
\hline \multicolumn{5}{|l|}{ Marital Status } \\
\hline Married & Base & & & \\
\hline Single & 0.85 & $(0.39,1.76)$ & & \\
\hline Co-habiting & 1.18 & $(0.39,3.18)$ & & \\
\hline $\begin{array}{l}\text { Separated, divorced } \\
\text { or widowed }\end{array}$ & 1.60 & $(0.83,3.03)$ & & \\
\hline \multicolumn{5}{|l|}{ Education } \\
\hline Third level & Base & & Base & \\
\hline Primary education & 6.59 & $\begin{array}{l}(3.10 \\
14.98)\end{array}$ & 3.96 & $\begin{array}{l}(1.44 \\
11.63)\end{array}$ \\
\hline Junior certificate ${ }^{b}$ & 2.57 & $(1.09,6.21)$ & 3.25 & $\begin{array}{l}(1.09 \\
10.09)\end{array}$ \\
\hline Leaving certificate ${ }^{c}$ & 4.04 & $(1.73,9.83)$ & 3.89 & $\begin{array}{l}(1.38 \\
11.57)\end{array}$ \\
\hline
\end{tabular}

Employment

$\begin{array}{lll}\text { Employed } & \text { Base } & \\ \text { Unemployed } & 5.31 & (2.56, \\ & & 11.61) \\ & & (3.67, \\ \text { Retired, ill or unable } & 7.58 & 16.62) \\ \text { to work } & & \\ \begin{array}{l}\text { Health Cover } \\ \text { Private health }\end{array} & \text { Base } & \\ \text { insurance } & & \\ \text { Medical card }^{d} & 7.81 & (1.90, \\ & & 33.42)\end{array}$

No health cover $\quad 1.97 \quad(0.58,9.06)$

Occupancy

\begin{tabular}{lcccc}
$\begin{array}{l}\text { Outright owner/ } \\
\text { Mortgage }\end{array}$ & Base & \multicolumn{3}{c}{ Base } \\
Renting privately & 2.02 & $(0.83,4.72)$ & 5.09 & $(1.36,19.83)$ \\
Renting-Council & 2.10 & $(1.17,3.77)$ & 3.09 & $(1.31,7.62)$
\end{tabular}

Number of people in household

$\begin{array}{lllll}1 & 3.01 & (1.41,6.47) & 2.77 & (0.91,8.72) \\ 2 & 1.46 & (0.77,2.75) & 0.95 & (0.40,2.22) \\ 3-5 & \text { Base } & & \text { Base } & \\ 6+ & 0.96 & (0.33,2.47) & 0.28 & (0.07,1.00)\end{array}$

Stress

No Base

Yes
$(1.16,3.89) \quad 1.35$
Table 5 Factors associated with poor self-rated health (Continued)

\begin{tabular}{|c|c|c|c|c|}
\hline \multicolumn{5}{|c|}{ Chronic illness } \\
\hline No & Base & & Base & \\
\hline Yes & 5.96 & $\begin{array}{l}(3.24 \\
11.57)\end{array}$ & 4.78 & $\begin{array}{l}(2.09 \\
11.64)\end{array}$ \\
\hline \multicolumn{5}{|l|}{ Disability } \\
\hline No & Base & & & \\
\hline Yes & 3.96 & $(2.08,7.64)$ & 2.07 & $(0.89,4.84)$ \\
\hline \multicolumn{5}{|l|}{ Smoker } \\
\hline No & Base & & & \\
\hline Yes & 1.21 & $(0.71,2.06)$ & & \\
\hline \multicolumn{5}{|l|}{ IPAQ } \\
\hline Active & Base & & & \\
\hline Inactive & 1.42 & $(0.83,2.43)$ & & \\
\hline \multicolumn{5}{|c|}{ Local hospital use } \\
\hline No & Base & & Base & \\
\hline Yes & 2.52 & $(1.45,4.53)$ & 2.01 & $(1.00,4.14)$ \\
\hline \multicolumn{5}{|c|}{ Household GP use } \\
\hline No & Base & & & \\
\hline Yes & 2.49 & $\begin{array}{l}(0.66 \\
16.22)\end{array}$ & & \\
\hline \multicolumn{5}{|c|}{ Social cohesion score } \\
\hline 5 or less & Base & & & \\
\hline $6-10$ & 0.51 & $(0.29,0.87)$ & 0.52 & $(0.25,1.05)$ \\
\hline
\end{tabular}

${ }^{a}$ Logistic regression - adjusting for other factors included in the model bJunior or intermediate certificate, technical or vocational training 'Leaving cert, A-Level

${ }^{d}$ State provided general medical (primary care) services (GMS) to those households on low income

${ }^{\mathrm{e}}$ Renting from or rent paid by health board/county council 
Neither attendance at a general practitioner nor social cohesion was related to SRH. This is contrary to other studies conducted in Ireland and internationally. An Irish study based on SLAN in 2002 reported that high levels of social trust independently reduced the risk of reporting poor mental health [68]. An evaluation of social cohesion and self rating of health using data from 29 high income countries from the 2000 World Value Survey also found an association between social capital and good health [69]. The difference in findings in the current research may be as a result of all participants being resident within the same area and being more likely to have a similar level of social cohesion.

The odds of primary carers reporting that there was someone in their home with a chronic illness were nearly 5 times greater for rating their health as poor than the odds of a primary carer who did not report that there was a person with a chronic illness in the household. This is consistent with other research which has demonstrated a link between SRH and people living with chronic diseases such as CVD [32], arthritis, diabetes [31], lung disease and stroke [26]. The way that the question was asked in the HANA survey means that we are unable to determine whether it was the primary carers themselves with a chronic illness. In future research it would be of interest to delineate whether a lower self-rating of health occurs from the simple presence of having a person with a chronic illness in the house rather than the respondent themselves having the chronic condition and that affecting their SRH.

Unemployed, retired or ill primary carers were more likely to indicate lower self-rating of health when compared to employed people. This relationship between selfrated health and employment status is stronger than that which has previously been reported in the literature. A systematic review of the factors in the trajectory of selfrating of health identified a moderate relationship between self-rating of health and employment status [70] while a study of patients with multiple sclerosis reported those with good self-rated health were 2.46 times more likely to be in employment [71]. The association between SRH and employment may be greater in this study due to the effects of a recent economic recession resulting in high levels of unemployment, particularly in deprived areas.

The odds of a primary carer who reported renting privately were five times greater, and the odds of a primary carer who reported renting through social welfare support, were three times greater to rate their health as poorer compared to the odds of those who indicated that they are the out-right owner or mortgage holder of their home. This adds to current literature which identifies the link between poorer self-rating of health and occupancy status, particularly for those who are renters
[72] although the strength of this link does not appear to have been previously identified.

In the current study, SRH was not associated with stress, gender or being a smoker. The number of stressful life events experienced is associated with poorer SRH [73]. A study of black American adults reported a significant association between SRH and stress [74]. In the current study, stress was significantly associated with SRH using crude OR but not significant using adjusted ORs. A recent systematic review examining factors of change and cumulative factors in SRH found that gender is only moderately associated with growing influences of SRH factors over time [70]. Furthermore, the authors found that being a man was an advantageous factor, but the strength and direction of the association was inconsistent; with the influence of gender being weak and consistent in some studies and strong with minor inconsistency in other studies. Smoking more than 100 cigarettes in an entire life span is associated with lower SRH in two studies with adolescents and Asian American adults [75, 76]. Contrary to this, research conducted in Spain and Catalonia did not find an association between smoking status and SRH [77]. Also it is important to note that in the current study caution must be exercised when interpreting results as $73 / 343$ houses had a least one missing value. This accounts for approximately $21 \%$ missing data.

This study had a very good response rate of $82 \%$ and replicated a study completed in the same area in 2001 by employing a random cluster sampling method to select households. Standardised questions were included where possible. We conducted a media awareness campaign and rigorously trained experienced interviewers to strengthen the methodology. The steering committee for the research included partnerships with a number of community groups working in the area.

Consideration must be given to the fact that the sample represents 13 electoral divisions in one deprived suburb of Dublin and is not nationally representative. However, the inclusion of questions such as social capital and SRH complimentary to European studies [9] and the Irish national census [15] allow the data to be compared in national and European contexts. Previous studies have highlighted a need for such data collected at the community level, rather than consistently at the aggregated population level [78] so that data can be mobilised and utilised as part of health improvement strategies at local level. Data was collected in the current study through face-toface interviewer administrated questionnaires. A weakness of previous research in the Republic of Ireland is that it has relied on self-completed postal questionnaires and had a lower response rate; and thus, it is possible that non-participants in the survey may have had differing patterns of health that would have impacted on the results [50]. 
This study employed a logistic regression model to investigate the relative importance of the effects of different factors on respondent's SRH. However, this approach requires that all relevant factors are included in the set of variables entered into the multiple regression and that the different factors are all measured on a comparable scale. Failure to account for non-health characteristics may bias the estimated associations between health factors and SRH and this will need to be considered.

A recent systematic review has highlighted the need for future work to focus on the effects of unemployment on SRH within subsections of a population, rather than in the population as a whole as has been done in the past $[79,80]$. It would be particularly interesting to track potential changes in SRH as people return to employment following a deep recession in Ireland.

\section{Conclusion}

Health planners and policy makers are increasingly asking for a feasible method to identify vulnerable persons with the greatest health needs. SRH is an easy to administer question at population level that can assist in identifying persons at risk of poor health. Limitations aside, this study demonstrates that educational attainment, employment status, household occupancy, numbers of people living within the household, chronic illness and local hospital use are significant in predicting whether a person rates their health as 'poor' or 'good'. Future health and social policies should be cognisant of the impact of both health and non-health related factors on perceived health status.

\section{Additional file}

Additional file 1: Copy of survey instrument. (DOCX $250 \mathrm{~kb}$ )

\begin{abstract}
Abbreviations
AUC, area under the curve; $\mathrm{Cl}$, confidence interval; CVD, cardiovascular disease; DI, deprivation Index; ED, electoral division; HANA, health assets and needs assessment; IPAQ, international physical activity questionnaire; OECD, organisation for economic cooperation and development; OR, odds ratio; ROC Curve, receiver operating characteristic curve; SAHRU, Small Area Health Research Unit; SLAN, survey of lifestyle, attitudes and nutritional survey; SRH, self-rated health
\end{abstract}

\section{Acknowledgements}

We wish to thank the Adelaide Health Foundation and Tallaght Hospital for funding this study. We would also like to thanks the Fettercairn Community Health Project for assistance with the piloting of the data collection instrument, South Dublin County Council for contribution to the survey instrument and Health Atlas within the Health Service Executive for helping us to obtain access to the Geo Directory for the sampling frame. We wish to thank the participants who partook in this research.

\section{Funding}

Grant funding from the Adelaide Health Foundation and Tallaght Hospital funded this research. Both funders were represented on the study Steering Committee. The funders had no role in the design of the study, analysis, and interpretation of the data or in writing the manuscript. FM received a Summer Student Scholarship from the Health Research Board, Ireland to collaborate with the research team on this project.
Availability of data and materials

Data can be obtained by contacting the author directly.

\section{Authors' contributions}

$C D, J B$ and LW conceived of the study. EDS performed the logistic mixed effects model. All authors participated in the design of the study and drafting of the manuscript. All authors read and approved the final manuscript.

\section{Authors' information}

The authors are health professionals and health service researchers. CD is a health psychologist and a health services and health policy researcher in Trinity College Dublin (TCD). EDS is a bio-statistician in TCD. LW has a masters in social policy and is a PhD student at Trinity College Dublin. FM is a medical student within the School of Medicine, TCD. JB is the Chair of Population Health Medicine in TCD and a public health physician.

\section{Competing interests}

The authors declare that they have no competing interests.

\section{Consent for publication}

Not applicable.

Ethics approval and consent to participate

Ethical approval for the study was obtained from the Research Ethics Committee of St. James's Hospital and Tallaght Hospital (reference: 2014/06 Chairman 7). Each participant, including both clinical staff and patients, provided written informed consent before participating in this research.

\section{Author details}

${ }^{1}$ Public Health \& Primary Care, Institute of Population Health Trinity College Dublin, Tallaght Cross, Dublin 24 D24 DH74, Ireland. ${ }^{2}$ School of Dental Science, Dublin Dental University Hospital, Trinity College, Lincoln Place, Dublin 2, Ireland.

Received: 15 April 2016 Accepted: 4 August 2016

Published online: 11 August 2016

\section{References}

1. Au N, Johnston DW. Self-assessed health: what does it mean and what does it hide? Soc Sci Med. 2014;121:21-8.

2. Cutler DM, Huang W, Lleras-Muney A. When does education matter? The protective effect of education for cohorts graduating in bad times. Soc Sci Med 1982. 2015;127:63-73

3. Hu A, Hibel J. Educational attainment and self-rated health in contemporary China: A survey-based study in 2010. Soc Sci J. 2013;50:674-80.

4. Hämmig $\mathrm{O}$, Gutzwiller $\mathrm{F}$, Kawachi I. The contribution of lifestyle and work factors to social inequalities in self-rated health among the employed population in Switzerland. Soc Sci Med 1982. 2014;121:74-84.

5. Drydakis $\mathrm{N}$. The effect of unemployment on self-reported health and mental health in Greece from 2008 to 2013: a longitudinal study before and during the financial crisis. Soc Sci Med 1982. 2015;128:43-51.

6. Badland H, Turrell G, Giles-Corti B. Who does well where? Exploring how self-rated health differs across diverse people and neighborhoods. Health Place. 2013;22:82-9.

7. Verhaeghe P-P, Tampubolon G. Individual social capital, neighbourhood deprivation, and self-rated health in England. Soc Sci Med 1982. 2012;75:349-57.

8. Lindström M, Moghaddassi M, Merlo J. Individual self-reported health, social participation and neighbourhood: a multilevel analysis in Malmö, Sweden. Prev Med. 2004:39:135-41.

9. Rocco L, Suhrcke M. Is social capital good for health? A European perspective. [Internet]. Copenhagen: WHO Regional Office for Europe; 2012. Available from: http://www.euro.who.int/en/publications/abstracts/is-social-capital-good-forhealth-a-european-perspective.

10. Habibov N, Weaver R. Endogenous social capital and self-rated health Results from Canada's General Social Survey. Health Sociol Rev J Health Sect Aust Sociol Assoc. 2014:23:219

11. Meyer OL, Castro-Schilo L, Aguilar-Gaxiola S. Determinants of mental health and self-rated health: a model of socioeconomic status, neighborhood safety, and physical activity. Am J Public Health. 2014;104:1734-41.

12. Schüz B, Wurm S, Schöllgen I, Tesch-Römer C. What do people include when they self-rate their health? Differential associations according to 
health status in community-dwelling older adults. Qual Life Res Int J Qual Life Asp Treat Care Rehabil. 2011;20:1573-80.

13. Idler EL, Benyamini Y. Self-rated health and mortality: a review of twenty-seven community studies. J Health Soc Behav. 1997;38:21-37.

14. DeSalvo KB, Bloser N, Reynolds K, He J, Muntner P. Mortality prediction with a single general self-rated health question. A meta-analysis. J Gen Intern Med. 2006;21:267-75.

15. Central Statistics Office. Census 2011 This is Ireland (Part 1) [Internet]. Dublin: Central Statistics Office; 2012. Available from: http://www.cso.ie/en/ census/census2011 reports/census2011thisisirelandpart1/.

16. Central Statistics Office. Profile 8 - Our Bill of Health [Internet]. Dublin: Central Statistics Office; 2012. p. 1-96.

17. OECD. Health at a Glance 2015: OECD Indicators [Internet]. Paris: OECD Publishing; 2015. Available from: http//dx.doi.org/10.1787/health_glance-2015-en.

18. Shadbolt B. Some correlates of self-rated health for Australian women Am J Public Health. 1997;87:951-6.

19. Adler NE, Boyce T, Chesney MA, Cohen S, Folkman S, Kahn RL, et al. Socioeconomic status and health. The challenge of the gradient. Am Psychol. 1994;49:15-24.

20. Mackenbach JP, Stirbu I, Roskam A-JR, Schaap MM, Menvielle G, Leinsalu M, et al. Socioeconomic inequalities in health in 22 European countries. N Engl J Med. 2008;358:2468-81.

21. Franzini L, Caughy M, Spears W, Fernandez Esquer ME. Neighborhood economic conditions, social processes, and self-rated health in low-income neighborhoods in Texas: a multilevel latent variables model. Soc Sci Med 1982. 2005;61:1135-50

22. Huisman $M$, van Lenthe F, Mackenbach J. The predictive ability of self-assessed health for mortality in different educational groups. Int J Epidemiol. 2007;36:1207-13.

23. Tamayo-Fonseca N, Quesada JA, Nolasco A, Melchor I, Moncho J, PereyraZamora P, et al. Self-rated health and mortality: a follow-up study of a Spanish population. Public Health. 2013;127:1097-104.

24. Fried LP, Kronmal RA, Newman AB, Bild DE, Mittelmark MB, Polak JF, et al. Risk factors for 5-year mortality in older adults: the Cardiovascular Health Study. JAMA. 1998;279:585-92.

25. Singh-Manoux A, Guéguen A, Martikainen P, Ferrie J, Marmot M, Shipley M. Self-rated health and mortality: short- and long-term associations in the Whitehall II study. Psychosom Med. 2007;69:138-43.

26. Latham K, Peek CW. Self-rated health and morbidity onset among late midlife U.S. adults. J Gerontol B Psychol Sci Soc Sci. 2013;68:107-16.

27. Fylkesnes $\mathrm{K}$. Determinants of health care utilization-visits and referrals. Scand J Soc Med. 1993;21:40-50.

28. Pijls LT, Feskens EJ, Kromhout D. Self-rated health, mortality, and chronic diseases in elderly men. The Zutphen Study, 1985-1990. Am J Epidemiol. 1993;138:840-8.

29. Idler EL, Russell LB, Davis D. Survival, functional limitations, and selfrated health in the NHANES I Epidemiologic Follow-up Study, 1992. First National Health and Nutrition Examination Survey. Am J Epidemiol. 2000;152:874-83.

30. Tomten SE, Høstmark AT. Self-rated health showed a consistent association with serum HDL-cholesterol in the cross-sectional Oslo Health Study. Int J Med Sci. 2007;4:278-87.

31. Hayes AJ, Clarke PM, Glasziou PG, Simes RJ, Drury PL, Keech AC. Can selfrated health scores be used for risk prediction in patients with type 2 diabetes? Diabetes Care. 2008:31:795-7.

32. Delpierre C, Lauwers-Cances V, Datta GD, Berkman L, Lang T. Impact of social position on the effect of cardiovascular risk factors on self-rated health. Am J Public Health. 2009;99:1278-84

33. Jylhä M. What is self-rated health and why does it predict mortality? Towards a unified conceptual model. Soc Sci Med 1982. 2009;69:307-16.

34. Huisman M, Deeg DJH. A commentary on Marja Jylhä's "What is self-rated health and why does it predict mortality? Towards a unified conceptual model"(69:3, 2009, 307-316). Soc Sci Med. 2010;70:652-4.

35. World Health Organization. International Classification of Functioning, Disability and Health. Geneva, Switzerland: World Health Organization; 2001.

36. Arnadottir SA, Gunnarsdottir ED, Stenlund H, Lundin-Olsson L. Determinants of self-rated health in old age: A population-based, cross-sectional study using the International Classification of Functioning. BMC Public Health. 2011;11:670.

37. Hansen AW, Beyer N, Flensborg-Madsen T, Grønbæk M, Helge JW. Muscle strength and physical activity are associated with self-rated health in an adult Danish population. Prev Med. 2013;57:792-8.
38. Froom P, Melamed S, Triber I, Ratson NZ, Hermoni D. Predicting selfreported health: the CORDIS study. Prev Med. 2004;39:419-23.

39. Fatma HG, Joan VA, Ajabshir S, Gustavo ZG, Exebio J, Dixon Z. Perceived stress and self-rated health of Haitian and African Americans with and without Type 2 diabetes. J Res Med Sci Off J Isfahan Univ Med Sci. 2013;18:198-204.

40. Forthofer MS, Janz NK, Dodge JA, Clark NM. Gender differences in the associations of self esteem, stress and social support with functional health status among older adults with heart disease. J Women Aging. 2001;13:19-37.

41. Møller L, Kristensen TS, Hollnagel H. Self rated health as a predictor of coronary heart disease in Copenhagen, Denmark. J Epidemiol Community Health. 1996;50:423-8.

42. Klein BE, Klein R, Moss SE. Self-rated health and diabetes of long duration. The Wisconsin Epidemiologic Study of Diabetic Retinopathy. Diabetes Care. 1998;21:236-40

43. Manor O, Matthews S, Power C. Self-rated health and limiting longstanding illness: inter-relationships with morbidity in early adulthood. Int J Epidemiol. 2001;30:600-7.

44. Jonnalagadda SS, Diwan S. Health behaviors, chronic disease prevalence and self-rated health of older Asian Indian immigrants in the U.S. J Immigr Health. 2005;7:75-83.

45. Undén $A-L$, Elofsson S. Do different factors explain self-rated health in men and women? Gend Med. 2006;3:295-308.

46. Lim W-Y, Ma S, Heng D, Bhalla V, Chew SK. Gender, ethnicity, health behaviour \& self-rated health in Singapore. BMC Public Health. 2007;7:184.

47. Idler EL, Angel RJ. Self-rated health and mortality in the NHANES-I Epidemiologic Follow-up Study. Am J Public Health. 1990;80:446-52.

48. Bath PA. Differences between older men and women in the self-rated health-mortality relationship. Gerontologist. 2003;43:387-395-375.

49. Layes A, Asada Y, Kepart G. Whiners and deniers - what does self-rated health measure? Soc. Sci. Med. 1982. 2012;75:1-9.

50. Kelleher CC, Friel S, Nic Gabhainn S, Tay JB. Socio-demographic predictors of self-rated health in the Republic of Ireland: findings from the National Survey on Lifestyle, Attitudes and Nutrition, SLAN. Soc Sci Med 1982. 2003;57:477-86.

51. Long J, O'Loughlin R, O'Keefe F, O'Dowd T. People living in Tallaght and their Health. A community based cross-sectional survey. 2002

52. Smith SM, Long J, Deady J, O'Keeffe F, Handy D, O'Dowd T. Adapting developing country epidemiological assessment techniques to improve the quality of health needs assessments in developed countries. BMC Health Serv Res. 2005;5:32.

53. Townsend P. Deprivation. J Soc Policy. 1987;16:125-46.

54. Attwood S, Morton K, Sutton S. Exploring equity in uptake of the NHS Health Check and a nested physical activity intervention trial. J Public Health Oxf Engl. 2015. doi:10.1093/pubmed/fdv070.pmid:26036701.

55. Kelly A, Teljeur C. The National Deprivation Index. For Health \& Health Services Research - Update 2013 [Internet]. Dublin: Trinity College Dublin; 2013. Available from: http://tinyurl.com/ca9y5k6.

56. Craig $C L$, Marshall $A L$, Sjöström M, Bauman AE, Booth ML, Ainsworth $B E$, et al. International physical activity questionnaire: 12-country reliability and validity. Med Sci Sports Exerc. 2003;35:1381-95.

57. Gauthier AP, Lariviere M, Young N. Psychometric properties of the IPAQ: a validation study in a sample of northern Franco-Ontarians. J Phys Act Health. 2009;6 Suppl 1:S54-60.

58. Department of Health. Health in Ireland - Key Trends 2014 [Internet]. Dublin: Department of Health; 2015. Available from: http://health.gov.ie/ publications-research/statistics/.

59. Agresti A. Categorical data analysis. 2nd ed. Hoboken, New Jersey: John Wiley \& Sons, Ltd; 2002.

60. Fox J, Weisberg S. An (R) Companion to Applied Regression [Internet]. California: Thousand Oaks; 2011. Available from: http://socserv.socsci. mcmaster.ca/jfox/Books/Companion.

61. CRAN. The Comprehensive R Archive Network [Internet]. Available from: https://cran.r-project.org/.

62. Bates D, Maechler M, Bolker B, Walker S. Ime4: Limear mixed-effects models using Eigen and S4. R package version 1.1-9 [Internet]. 2015. Available from: https://cran.r-project.org/.

63. Robin X, Turck N, Hainard A, Tiberti N, Lisacek F, Sanchez C, et al. pRoc: Display and analyze ROC curves. [Internet]. 2015. Available from: https:/ cran.r-project.org/web/packages/pROC/pROC.pdf

64. Vie TL, Hufthammer KO, Holmen TL, Meland E, Breidablik HJ. Is self-rated health a stable and predictive factor for allostatic load in early adulthood? 
Findings from the Nord Trøndelag Health Study (HUNT). Soc Sci Med 1982. 2014;117:1-9.

65. Groot W. Adaptation and scale of reference bias in self-assessments of quality of life. J Health Econ. 2000;19:403-20.

66. Rohrer JE, Bernard ME, Zhang Y, Rasmussen NH, Woroncow H. Marital status, feeling depressed and self-rated health in rural female primary care patients. J Eval Clin Pract. 2008;14:214-7.

67. Zheng H, Thomas PA. Marital status, self-rated health, and mortality: overestimation of health or diminishing protection of marriage? J Health Soc Behav. 2013;54:128-43.

68. Fitzsimon N, Johnson H, Hayes C, Mulholland D, Kelleher CC. Predictors of poor self-rated health at area level in the Eastern Regional Health Authority: a multilevel analysis. Ir Med J. 2007;100(suppl):47-9.

69. Chuang Y-C, Chuang K-Y, Yang T-H. Social cohesion matters in health. Int J Equity Health. 2013;12:87.

70. Cullati S, Rousseaux E, Gabadinho A, Courvoisier DS, Burton-Jeangros C. Factors of change and cumulative factors in self-rated health trajectories: a systematic review. Adv Life Course Res. 2014;19:14-27.

71. Krokavcova M, Nagyova I, Van Dijk JP, Rosenberger J, Gavelova M, Middel B, et al. Self-rated health and employment status in patients with multiple sclerosis. Disabil Rehabil. 2010;32:1742-8.

72. Pollack CE, Griffin BA, Lynch J. Housing affordability and health among homeowners and renters. Am J Prev Med. 2010;39:515-21.

73. Demirchyan A, Petrosyan V, Armenian HK, Khachadourian V. Prospective study of predictors of poor self-rated health in a 23-year cohort of earthquake survivors in Armenia. J Epidemiol Glob Health. 2015;5:265-74.

74. Savoy EJ, Reitzel LR, Nguyen N, Advani PS, Fisher FD, Wetter DW, et al. Financial strain and self-rated health among Black adults. Am J Health Behav. 2014;38:340-50

75. Wang MP, Ho SY, Lo WS, Lai MK, Lam TH. Smoking is associated with poor self-rated health among adolescents in Hong Kong. Nicotine Tob Res Off J Soc Res Nicotine Tob. 2012;14:682-7.

76. Tran TV, Nguyen D, Chan K, Nguyen T-N. The association of self-rated health and lifestyle behaviors among foreign-born Chinese, Korean, and Vietnamese Americans. Qual Life Res Int J Qual Life Asp Treat Care Rehabil. 2013;22:243-52.

77. Arroyo E, Renart G, Saez M. How the economic recession has changed the likelihood of reporting poor self-rated health in Spain. Int J Equity Health. 2015;14:149.

78. McLean J. Putting Asset Based Approaches Into Practice: Identification, mobilisation and measurement of assets. [Internet]. Glasgow: Glasgow Centre for Population Health; 2012. Available from: http://www.gcph.co.uk/ assets/0000/3433/GCPHCS10forweb_1_.pdf.

79. Norström F, Virtanen P, Hammarström A, Gustafsson PE, Janlert U. How does unemployment affect self-assessed health? A systematic review focusing on subgroup effects. BMC Public Health. 2014;14:1310.

80. Gunasekara Fl, Carter K, Blakely T. Change in income and change in selfrated health: Systematic review of studies using repeated measures to control for confounding bias. Soc Sci Med 1982. 2011;72:193-201.

\section{Submit your next manuscript to BioMed Central and we will help you at every step:}

- We accept pre-submission inquiries

- Our selector tool helps you to find the most relevant journal

- We provide round the clock customer support

- Convenient online submission

- Thorough peer review

- Inclusion in PubMed and all major indexing services

- Maximum visibility for your research

Submit your manuscript at www biomedcentral.com/submit
() Biomed Central 